\title{
Hemşirelik Bölümü Üçüncü ve Dördüncü Sınıf Öğrencilerinin Profesyonel Davranışlarının İncelenmesi
}

\section{Investigation of Professional Behavior of Third and Fourth Grade Students of Nursing Department}

\author{
${ }^{1}$ Dilek YILMAZ, ${ }^{1}$ Esra POLATDEMIR \\ ${ }^{1}$ Bursa Uludağ Üniversitesi, Sağlık Bilimleri Fakültesi, Hemşirelik Bölümü, Bursa
}

Dilek Yllmaz: https://orcid.org/0000-0001-7269-8493

Esra Polatdemir: https://orcid.org/0000-0001-8154-6408

\section{ÖZ}

Amaç: Bu çalışmanın amacı; hemşirelik bölümü üçüncü ve dördüncü sinıfta öğrenim gören öğrencilerin profesyonel davranışlarının ve bunu etkileyen değişkenlerin belirlenmesidir.

Materyal ve Metot: Araştırma, 2018-2019 EğitimÖğretim Bahar yarıyılında Bursa Uludağ Üniversitesi Sağlık Bilimleri Fakültesi Hemşirelik Bölümü üçüncü ve dördüncü sınıf öğrencileri üzerinde yürütüldü. Araştırmanın örneklemini araştırmanın yapıldığı tarihlerde ulaşılabilen ve araştırmaya gönüllü katılmayı kabul eden 180 öğrenci olușturdu. Araștırma verileri "Öğrenci Tanıtım Formu" ve "Hemşirelik Öğrencileri Profesyonel Davranış Ölçeği (HÖPTÖ)" ile toplanıldı.

Bulgular: Araștırmaya katılan öğrencilerin yaş ortalama-

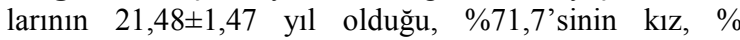
63,9'unun üçüncü sinıfta öğrenim gördüğü, \%63,9'unun isteyerek hemşirelik mesleğini tercih ettiği, \%68,3'ünün hemşirelik mesleğini sevdiği, \%46,7'sinin hemşirelik mesleğini değiștirmek istemedikleri bulundu. Öğrencilerin HÖPTÖ toplam puan ortalamaları 117,95 $\pm 12,84$ (min:56, max: 135) olarak saptandı. Kız öğrencilerin, hemșirelik mesleğini isteyerek tercih edenlerin, hemşirelik mesleğini sevenlerin, mesleki eğitimin profesyonel davranışlarını geliştirmede etkili olduğunu düşünenlerin ve mesleğini değiştirmeyi istemeyenlerin HÖPTÖ toplam puan ortalamaları diğer öğrencilere göre istatistiksel olarak anlamlı derecede yüksek bulundu $(\mathrm{p}<0,05)$.

Sonuç: Yapılan bu araștırma sonucunda; hemșirelik bölümünde öğrenim gören üçüncü ve dördüncü sınıf öğrencilerinin profesyonel davranışları uygulayabilme düzeyinin yüksek olduğu belirlendi.

Anahtar Kelimeler: Hemșirelik öğrencileri, profesyonellik, profesyonel davranış

\section{ABSTRACT}

Objective: The aim of this study was to determine the professional behaviors of nursing department students studying in their third and fourth years, and the factors affecting them.

Materials and Methods: The study was conducted with third and fourth-year students in the Nursing Department of Bursa Uludağ University Health Sciences Faculty during the academic year in the Spring semester 2018-2019. The research sample consisted of the 180 students who could be contacted on the dates the research was conducted and who agreed voluntarily to participate in the study. A "Student Description Form" and the "Nursing Students' Professional Behavior Scale (NSPBS)" were used to collect research data.

Results: It was found that the average age of the students participating was $21,48 \pm 1,47$ years, $71,7 \%$ were female, $63,9 \%$ were in their third year of study, $63,9 \%$ had chosen the nursing profession willingly, $68,3 \%$ liked the nursing profession, and $46.7 \%$ did not want to change their profession. The students' total NSPBS score mean was found to be $117,95 \pm 12,84$ (min: 56 , max: 135). Statistically significantly higher NSPBS total mean scores compared to other students were found with female students, those who had chosen the nursing profession willingly, those who liked the nursing profession, those who thought that professional training had an effect on professional behaviors and those who did not want to change their profession $(\mathrm{p}<0,05)$.

Conclusion: As a conclusion of the study, it was found that the level of ability to conform to professional behaviors in third and fourth-year students at the nursing department was high.

Keywords: Nursing students, professionalism, professional behavior

Yayın Bilgisi / Article Info:

Gönderi Tarihi/ Received: 17/06/2019

Sorumlu Yazar / Corresponding Author:

Dilek Yilmaz

Kabul Tarihi/ Accepted: 24/09/2019

Bursa Uludağ Üniversitesi, Sağlık Bilimleri Fakültesi, Hemşirelik Bölümü, Bursa.

Online Yayın Tarihi/ Published: 30/06/2020

Telefon No: 02242942454

E-mail: dilekk@uludag.edu.tr

*Atıf/ Cited: Yılmaz D, Polatdemir E. Hemșirelik Bölümü Üçüncü ve Dördüncü Sınıf Öğrencilerinin Profesyonel Davranıșlarının İncelenmesi. Online Türk Sağllk Bilimleri Dergisi 2020;5(2):281-288. doi: 10.26453/otjhs.578577

*Bu çalışma 25-27 Nisan 2019 tarihleri arasında Afyonkarahisar'da düzenlenen 18.Ulusal Hemşirelik Öğrencileri Kongresi'nde poster bildiri olarak sunulmuştur. 


\section{GíRiș}

Geçmişten gelen birikimlerin ortaya çıardığ 1 gelişmeler, her alanda yeni anlayış ve yaklaşım biçimlerini de beraberinde getirmektedir. ${ }^{1} \mathrm{Bu}$ doğrultuda profesyonellik kavramı ön plana çıkmaktadır. Literatürde profesyonellik kavramının birçok tanımına rastlamak mümkündür. En genel tanımıyla profesyonellik; alanında eğitim almış uzman kişilerce yürütülen, ilgili meslek örgütleriyle desteklenerek uygulanan, yetkinlikleri içeren bir tutum ve bakış açısı sağlayan standart bir davranış biçimidir. ${ }^{2-4}$ Mesleki profesyonellik ise; bireysel profesyonelliğin örgütsel profesyonelliğe yerini bırakmasıdır. ${ }^{2,5,6}$ Mesleki profesyonellik, mesleğin standartlarının oluşturulmasında ve kaliteli bakım sunulmasında önemlidir. ${ }^{7}$

Son yıllarda gerçekleşen teknolojik ve politik gelişmeler sağllk sistemini de etkilemekte olup, sağlık sisteminin hizmet sunucularından birisi olan hemşirelerin rol ve işlevlerinde değişiklik meydana getirmektedir. Özellikle tedavi edici hizmetlerden çok koruyucu hizmetlerin ön plana çıkması, hasta bireyden sağlıklı birey ve ailesine yönelmeyi gerektirmektedir. Bu durum hemşirenin görev ve sorumluluklarını etkilemektedir. Bakım verici rolünün yanı sıra eğitici, danışman, karar verici, yönetici ve koordinatör rollerini ön plana çıkarmaktadır. Böylece hemşirelik mesleği geleneksel hemşirelik modelinden profesyonelliğe doğru bir süreç yaşamaktadır. ${ }^{2,8}$ Profesyonellik, mesleğe ilişkin standartlarının belirlenmesinde ve hemşirelik mesleğinde nitelikli bakım sunulmasında oldukça önemlidir. ${ }^{1,3,9}$ Bir mesleğin profesyonel olup olmadığını belirleyen en önemli ölçütlerden biri eğitim ve öğretimin niteliğidir. Hemşirelik eğitimi ile öğrencilerin özgür düşüncelerini geliştirmek, bireysel, profesyonel, etik değerlerini netleştirmek ve mesleki bilinçlerini geliştirmek amaçlanmaktadır. ${ }^{10}$ Hemşirelik eğitimi bilimsel bir kökene dayalı bilgi, klinik beceri, eleştirel düşünme ve kişilerarası iletişimi içinde barındırmaktadır. Hemşireliğin profesyonelleşmesinde eğitim çok önemli bir yere sahiptir. ${ }^{11}$ Öğrencilik yıllarında hemşirelik mesleğinin bilincini oturtmak meslek hayatında profesyonelliği de beraberinde getirmesi bakımından önemlidir. ${ }^{12}$

Sağlık bakım hizmetlerinin kaliteli bir şeklide sunulması hemşirelerin profesyonel tutumları ile mümkün olabilecektir. ${ }^{1,13,14} \mathrm{Bu}$ nedenle eğitim-öğretim sürecinin, hemşirelik öğrencilerinin profesyonel davranışları kazanacak şekilde yapılandırılması önemlidir. Mezun konumuna yaklaşan hemşirelik öğrencilerinin profesyonel davranışlarının belirlenmesine gereksinim olduğu düşünülmektedir. Bu doğrultuda bu çalışmada; hemşirelik bölümü üçüncü ve dördüncü sınıfta öğrenim gören öğrencilerin profesyonel davranışlarının ve bunu etkileyen değişkenlerin belirlenmesi amaçlanmaktadır. $\mathrm{Bu}$ araştırma sonucundan elde edilecek verilerin literatüre katkı sağlayacağı düşünülmektedir.

\section{MATERYAL VE METOT}

Araştırmanın Tipi: Tanımlayıcı ve kesitsel tipte bir çalışmadır.

Etik Komite Onayı: Çalışmamız Bursa Uludağ Üniversitesi Sağlık Bilimleri Araştırma ve Yayın Etik Kurulu (Tarih 12/02/2019, karar no: 2019/03) tarafindan onaylandi.

Araştırmanı Evren ve Örneklemi: Araştırmanın evrenini, 2018-2019 Eğitim-Öğretim yılı Bahar yar1yılında Bursa Uludağ Üniversitesi Sağlık Bilimleri Fakültesi Hemşirelik Bölümü’nde kayıtlı üçüncü ve dördüncü sınıf öğrencileri ( $\mathrm{n}=270)$, araştırmanın örneklemini ise araştırmanın yapıldığı tarihlerde ulaşılabilen ve araştırmaya katılmayı gönüllü olarak kabul eden 180 öğrenci oluşturdu (Katılım yüzdesi: \%65,69). Örnekleme dahil edilen öğrencilerin seçiminde tabakalı rastgele örnekleme yöntemi kullanıldı. Hangi öğrenciye anket uygulanacağ $ı$ basit rastgele yöntemi kullanılarak belirlendi.

Veri Toplama Araçları: Araştırma verileri "Öğrenci Tanıtım Formu" ve "Hemşirelik Öğrencileri Profesyonel Davranış Ölçeği (HÖPTÖ)" ile toplanıldı.

Öğrenci Tanıtım Formu: Araştırmacılar tarafından hazırlanan bu formda; öğrencilerin yaşı, cinsiyeti, sınıfi, mezun olduğu lise, hemşirelik mesleğini tercih etme, hemşireliği sevme, mesleği değiştirme ve mesleki eğitimin profesyonel davranışları geliştirmede etkili olma durumu gibi sorulara yer verildi.

Hemşirelik Öğrencileri Profesyonel Davranış Ölçe$\breve{g} \boldsymbol{i}$ (HÖPTÖ): Göz ve Geçkil ${ }^{10}$ tarafindan 2010 yılında geliştirilen bu ölçek; toplamda 27 maddeden oluşmakta olup, sağlık-bakım uygulamaları (18 madde), aktivite uygulamaları (7 madde) ve raporlama (2 madde) olmak üzere üç alt boyutu içeren, beşli likert tipte bir ölçüm aracıdır. Ölçekte maddelerin puanlanması "Oldukça Yeterli" $=5$, "Kısmen Yeterli"=4, "Kararsızım"=3, "Yetersiz" $=2$ ve "Oldukça Yetersiz" $=1$ şeklindedir. Yirmi yedi madde puanının toplamı, toplam HÖPTÖ puanını verir. Toplam puan 27- 135 arası bir değere sahiptir. Ölçek puanının yüksek olması öğrencilerin profesyonel davranışları uygulayabilme düzeylerinin yüksek olduğunu göstermektedir. ${ }^{15}$ Ölçeğin Cronbach Alfa değeri 0,95 olarak bulunmuştur ${ }^{10}$. Bu çalışmada ise Cronbach Alfa değeri 0,93 olarak hesapland. 
Verilerin Toplanması: Öğrencilere araştırmanın amacı anlatılarak, gönüllü olarak araştırmaya katılmak isteyen öğrencilerin bilgilendirilmiş onayları alındı. Anketlerin doldurulduğu sürenin öğrencilerin ders saatlerini etkilememesine dikkat edildi. Öğrencilere; verilerin tümünün bilimsel çalışma için kullanılacağı anlatılıp, yanıtların hiçbir şekilde ders notlarını etkilemeyeceği açıklandı. Anket formları öğrencilere dağıtıldı ve soruların yanıtlamalarını bitiren ögrencilerden formlar geri toplanıp, değerlendirmeye alınd 1 .

Verilerin Değerlendirilmesi: Araştırma verilerinin değerlendirilmesi SPSS (Statistical Package For Social Science) 22.0 paket programı kullanılarak yapıldı. Verilerin analizinde sayı, yüzde, ortalama ve standart sapma hesaplandı. Ölçek puanının normal dağılıma uygunluğunu belirlemek için KolmogorovSmirnov testi kullanıldı. Ölçek puanının normal dağllım göstermemesi nedeniyle parametrik olmayan testlerden iki bağımsız değişken için Mann-Whitney U testi, ikiden fazla bağımsız değişken için KruskalWallis testi kullanıldı. Araştırmada istatistiksel anlamlılık düzeyi $\mathrm{p}<0.05$ olarak kabul edildi.

\section{BULGULAR}

Araştırmaya katılan öğrencilerin yaş ortalamalarının 21,48 $\pm 1,47$ y1l olduğu, $\% 71,7$ 'sinin k1z, $\% 63,9$ 'unun üçüncü sınıfta öğrenim gördüğü, \%53,9'unun Anadolu-Fen Lisesi mezunu olduğu, \%63,9'unun isteyerek hemşirelik mesleğini tercih ettiği, \%68,3'ünün hemşirelik mesleğini sevdiği, \%58,9'unun aldıkları mesleki eğitimin profesyonel davranışlarını geliştirmede etkili olduğunu düşündükleri, $\% 46,7$ 'sinin hemşirelik mesleğini değiştirmek istemedikleri bulundu (Tablo 1).

Araştırmaya dahil edilen üçüncü ve dördüncü sınıf hemşirelik öğrencilerinin HÖPTÖ toplam puan orta-

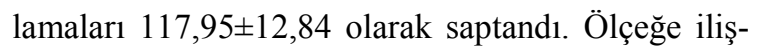
kin alt boyut puan ortalamaları değerlendirildiğinde, sağlık bakım uygulamaları alt boyutu puan ortalama$\sin ı$ 1n $80,72 \pm 8,67$, aktivite uygulamaları puan ortalamasinın $28,88 \pm 3,75$ ve raporlama puan ortalamas1nın $8,34 \pm 1,77$ olduğu bulundu (Tablo 2).

Araştırmada; kız öğrencilerin, hemşirelik mesleğini isteyerek tercih eden, hemşirelik mesleğini seven, mesleki eğitimin profesyonel davranışlarını geliştirmede etkili olduğunu düşünen ve mesleğini değiş̧tirmeyi istemeyen öğrencilerin HÖPTÖ toplam puan ortalamaları diğer öğrencilere göre istatistiksel açıdan anlamlı derecede yüksek bulundu ( $\mathrm{p}<0,05$, Tablo 3). Diğer yandan öğrencilerin, öğrenim gördükleri sınıf ve mezun oldukları lise türü değişkenlerinin
HÖРTÖ toplam puan ortalamalarını etkilemediği belirlendi ( $\mathrm{p}>0,05$, Tablo 3 ).

\section{TARTISSMA VE SONUÇ}

Hemşirelik eğitimi profesyonel davranışın geliştirilmesinde şüphesiz ki önemli bir yere sahiptir. ${ }^{12,16}$ Profesyonel davranış gelişimi öğrencilikte okul eğitimi ile beraber başlamakta olup, çalışma yaşantısı içinde gelişmeye devam etmektedir. ${ }^{12,17}$ Öğrencilerin profesyonel davranışları klinik alana aktarabilmesi, eğitim sürecinde profesyonellik algısının oluşması, gelişmesi ve hasta bakımına yansıtılması için uygun fırsatların yaratılması önemlidir. Bu süreçte profesyonelliği etkileyen faktörlerin belirlenmesinin, hemşirelik öğrencilerinin eğitim yaşantılarının şekillendirilmesinde yol gösterici olacağı bildirilmektedir. ${ }^{15}$ Hemşirelik bölümü üçüncü ve dördüncü sınıfta öğrenim gören öğrencilerin profesyonel davranışlarının ve bunu etkileyen değişkenlerin belirlenmesi amacıyla yapılan bu çalışma sonucunda; öğrencilerin HÖPTÖ toplam puan ortalamaları $117,95 \pm 12,84$ olarak bulundu. Ölçekten alınabilecek en yüksek puan 135 olduğu düşünüldüğünde, bu çalışmada hemşirelik öğrencilerinin profesyonel davranışları uygulayabilme düzeylerinin yüksek olduğu söylenebilir. Konuyla ilgili yapılan benzer çalışmalar incelendiğinde; Göz ve Geçkil ${ }^{10}$ 'in HÖPTÖ’nün geçerlik güvenirliğini test etmek amacıyla yaptıkları çalışmada, ögrencilerin HÖPTÖ toplam puan ortalaması $113,49 \pm 18,47$ olarak bulunmuştur. Çevik ve Khorshid $^{18}$ 'in üçüncü ve dördüncü sinıfta okuyan hemşirelik öğrencilerinin profesyonel davranışları uygulayabilme durumların belirlemek amaciyla yaptıkları bir çalışmada HÖPTÖ toplam puan ortalamas1 116,73+13,62 olarak saptanmıştır. Cerit ve Temelli ${ }^{15}$ 'in çalışmasında da HÖPTÖ toplam puan

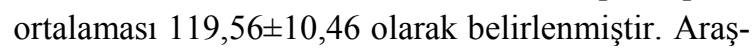
tırma sonucumuzun, yapılan bu çalışmaların sonuçlarıyla benzerlik taşıdığı görülmektedir.

Yaptığımız bu çalışma sonucunda kız öğrencilerin HÖPTÖ toplam puan ortalamaları erkek öğrencilere göre anlamlı derecede yüksek bulundu. Konuyla ilgili yapılan çalışmaların bulguları ile çalışma sonucumuz benzerlik taşımaktadır. ${ }^{10,15,19-21}$ Diğer yandan, yapılan bazı çalışmalarda ise cinsiyet faktörünün profesyonelliği etkilemediği bildirilmiştir. ${ }^{8,22}$ Çalışmalar arasındaki bu farklılığın nedeninin, erkek öğrencilerin mesleki profesyonelliğe yönelik bakış açısı özelliklerinden kaynaklandığı düşünülmektedir. $\mathrm{Ak}$ ve ark. ${ }^{12}$ bildirdiğine göre ülkemizde yürütülen bazı çalışmalarda erkek öğrencilerin çoğunun hemşirelik mesleğini iş bulma kolaylığı nedeniyle tercih 
ettikleri bildirilmektedir. ${ }^{23,24}$ Dolayısıyla bu durumun erkek öğrencilerin profesyonel davranışlarının kız öğrencilere göre daha olumsuz etkileyebileceğini düşündürmüştür.

Mesleği isteyerek tercih etme ve mesleği sevme; öğrencinin hem öğrencilik yaşantısında hem de mesleki yaşantısında daha başarılı olmasına, mesleği severek yapmasına, mesleğini içselleştirmesine, mesleki bilgi ve becerilerini geliştirmesine dolayısıyla olumlu benlik saygısı oluşturmasına ve profesyonelliğe olumlu katkı sağlamaktadır. ${ }^{24-26}$ Ayrıca kişinin başarılı olabilmesi, mesleğini bilerek ve isteyerek seçmiş olmasıyla yakından ilişskilidir. ${ }^{18}$ Çalışma sonucunda hemşirelik mesleğini isteyerek tercih eden, hemşirelik mesleğini seven ve mesleğini değiştirmeyi istemeyen öğrencilerin diğer öğrencilere göre profesyonel davranışları uygulayabilme düzeylerinin yüksek olduğu belirlendi. Literatürde var olan çalışmalarda da benzer bulgulara rastlanmıştır. ${ }^{12,18,24}$ Diğer yandan çalışma örneklemine hemşirelerin dahil edildiği çalışmalarda da mesleğinden memnun olan hemşirelerin profesyonellik tutumlarının daha iyi düzeyde olduğu bulunmuştur. ${ }^{5,6,24}$ Dikmen ve ark. ${ }^{24}$ yaptığı işi severek yapmanın aynı zamanda iş doyumunu, yapılan işten duyulan memnuniyeti arttırdığını ve motive bir şekilde çalışmanın ise profesyonelliği de beraberinde getirdiğini bildirmişlerdir.

Hemşirelik eğitimi ile öğrencilerin özgür düşüncelerini geliştirmek, bireysel, profesyonel, etik değerlerini netleştirmek ve mesleki bilinçlerini geliştirmek amaçlanmaktadır. ${ }^{10}$ Hemşirelik eğitimi bilimsel bir kökene dayalı bilgi, klinik beceri, eleştirel düşünme ve kişilerarası iletişimi içinde barındırmaktadır. Hemşireliğin profesyonelleşmesinde eğitim çok önemli bir yere sahiptir. ${ }^{11}$ Çalışmaya katılan öğrencilerden mesleki eğitimin profesyonel davranışlarını geliştirmede etkili olduğunu düşünenlerin HÖPTÖ toplam puan ortalaması diğer öğrencilere göre anlamlı olarak daha yüksek bulundu. Bu durum, mesleki eğitim bilincine sahip olmanın profesyonelliğe olumlu yansıdığı şeklinde yorumlanmıştır.

Çalışma sonucunda; istatistiksel olarak anlamlı olmamasına rağmen, üçüncü sınıf öğrencilerinin dördüncü sınıf öğrencilere, düz lise mezunu öğrencilerin ise sağlık meslek lisesi mezunu öğrencilere göre profesyonel davranışları uygulayabilme düzeyleri daha yüksek bulunmuştur. Bu durum son sınıfta öğrencilerin iş bulma kaygısı taşıması ve lisedeki eğitim müfredatı farklılıkları gibi nedenlerin öğrencilerin profesyonellik davranışlarını etkileyebilir şeklinde tahmin edilmiştir. Konuyla ilgili yapılan çalışma- lar incelendiğinde ise çalışmaların bazılarında son sınıf öğrencilerin profesyonellik düzeyleri, diğer sınıflarda öğrenim gören öğrencilere göre daha düşük bulunmuştur. ${ }^{12,19,27}$ Yapılan diğer çalışmalarda ise son sınıf öğrencilerinin profesyonellik düzeylerinin diğer sınıflardaki öğrencilere göre, ${ }^{15,18,20,22}$ düz lise mezunu öğrencilerin sağlık meslek lisesi öğrencilere göre profesyonellik düzeylerinin yüksek olduğu bildirilmiştir. ${ }^{5,18}$ Çalışma sonuçları arasındaki bu farklılıkların; çalışmalara dahil edilen katılımcıların özelliklerinden ve hemşirelik eğitimindeki müfredat farklılıklarından kaynakladığı düşünülmektedir.

Çalışma sonucunda; hemşirelik bölümünde öğrenim gören üçüncü ve dördüncü sınıf öğrencilerinin profesyonel davranışları uygulayabilme düzeyi yüksek bulundu. Ayrıca, cinsiyet, hemşirelik mesleğini isteyerek tercih etme, hemşirelik mesleğini sevme, mesleki eğitimin profesyonel davranışlarını geliştirmede etkili olduğunu düşünme ve mesleğini değiştirmeyi istememe gibi durumların profesyonel davranışları uygulayabilme düzeyini olumlu yönde etkilediği belirlendi. $\mathrm{Bu}$ sonuçlar doğrultusunda; hemşirelik müfredat programlarında profesyonellik konusuna ağırlık verilmesi, mesleki eğitim sürecinde öğrencilere motivasyon programlarının oluşturulması ve araştırmanın daha geniş bir örneklemde, farklı değişkenleri de ele alarak karşılaştırmalı olarak yapılması önerilmektedir.

Etik Komite Onayı: Çalışmamız Bursa Uludağ Üniversitesi Sağlık Bilimleri Araştırma ve Yayın Etik Kurulu (Tarih 12/02/2019, karar no: 2019/03) tarafindan onaylandi.

Çıkar Çatışması: Yazarlar çıkar çatışması bildirmemişlerdir.

Yazar Katkıları: Fikir - DY, EP; Veri toplanması ve/veya işlemesi - EP, DY; Analiz ve/veya yorum DY; Yazıyı yazan - DY.

Hakem değerlendirmesi: Dış bağımsız.

Teşekkür: Yazarlar, çalışmaya katılan tüm öğrencilere teşekkür eder.

\section{KAYNAKLAR}

1. Demir S, Yıldırım NK. Psikiyatri hemşirelerinin profesyonel davranışlarının belirlenmesi. Psikiyatri Hemşireliği Dergisi. 2014;5(1):25-32.

2. Adıgüzel O, Tanrıverdi H, Özkan DS. Mesleki profesyonellik ve bir meslek mensupları olarak hemşireler örneği. Yönetim Bilimleri Dergisi. 2011;9(2):238-259.

3. Zengin M, Yayan EH, Yıldırım N, Akın E, Avşar Ö, Mamiş E. Pediatri hemşirelerinin profesyonel 
değerlerinin profesyonel tutumlarına etkisi. HSP. 2018;5(3):316-323.

4. Farhadi A, Elahi N, Jajali R. The effect of professionalism on the professional communication between nurses and physicians: a phenomenological study. Journal of Nursing and Midwifery Sciences. 2016;3(3):18-26.

5. Beydağ KD, Arslan H. Kadın Doğum kliniklerinde çalışan ebe ve hemşirelerin profesyonelliklerini etkileyen faktörler. Fırat Sağlık Hizmetleri Dergisi. 2008;3(7):75-87.

6. Karamanoğlu AY, Özer FG, Tuğcu A. Denizli ilindeki hastanelerin cerrahi kliniklerinde çalışan hemşirelerin mesleki profesyonelliklerinin değerlendirilmesi. Firat Tıp Dergisi. 2009;14(1):12-17.

7. Erbil N, Bakır A. Mesleki profesyonel tutum envanterinin geliştirilmesi. Uluslararası İnsan Bilimleri Dergisi. 2009;6(1):290-302.

8. Dinç S, Kaya Ö, Şimşek Z. Harran üniversitesi sağlık yüksekokulu öğrencilerinin hemşirelik mesleği hakkındaki bilgi, düşünce ve beklentileri. Atatürk Üniversitesi Hemşirelik Yüksekokulu Dergisi. 2007;10(1):1-9.

9. Çelik S, Ünal Ü, Saruhan S. Cerrahi kliniklerde çalışan hemşirelerin mesleki profesyonelliklerinin değerlendirilmesi. Florence Nightingale Hemşirelik Dergisi. 2012;20(3):193-199.

10. Goz F, Geckil E. Nursing students professional behaviors scale validity and reliability. Pakistan Journal of Medical Science. 2010;26(4):938-941.

11. Karagözoğlu Ş. Bilimsel bir disiplin olarak hemşirelik. Cumhuriyet Üniversitesi Hemşirelik Yüksek Okulu Dergisi. 2005;9(1):6-14.

12. Ak B, Cerit B, Dikmen Y, Erol F. Hemşirelik öğrencilerinin profesyonel tutumları ve etkileyen faktörler. Sted. 2018;27(4):232-242.

13. Okuroğlu GK, Bahçecik N, Alpar ŞE. Felsefe ve hemşirelik etiği. Kilikya Felsefe Dergisi. 2014;1 (1):53-61.

14. Uslu Ö. Hemşirelerin mesleki profesyonelliklerinin değerlendirilmesi. Okan Üniversitesi Sağlık Bilimleri Enstitüsü Hemşirelik Anabilim Dalı, Yüksek Lisans Tezi, İstanbul, 2018.

15. Cerit B, Temelli G. Hemşirelik öğrencilerinde profesyonel davranışların cinsiyet ve sınıf düzeyine göre incelenmesi. Sağlık ve Hemşirelik Yönetimi Dergisi. 2018;5(3):164-171.

16. İnce $\mathrm{S}$, Khorshid L. Hemşirelik öğrencilerinin meslek seçimini etkileyen faktörlerin belirlenmesi. Anadolu Hemşirelik ve Sağlık Bilimleri Dergisi 2015;18(3):163-171.
17. Deppoliti, D. Exploration how new registered nurses construct professional identity in hospital settings. The Journal of Continuing Education in Nursing. 2008;39(6):255-262.

18. Çevik K, Khorshid L. Hemşirelik öğrencilerinin profesyonel davranışları uygulayabilme durumlarının belirlenmesi. Ege Üniversitesi Hemşirelik Fakültesi Dergisi. 2012;28(2):23-30.

19. Karadağlı F. Hemşirelik öğrencilerinin profesyonel değer algıları ve etkileyen faktörler. Mersin Üniversitesi Sağlık Bilimleri Dergisi. 2016;9 (2):841-91.

20. Bang KS, Kang JH, Jun MH, et al. Professional values in Korean undergraduate nursing students. Nurse Education Today. 2011;31(1):72-75.

21. Rose T, Nies MA, Reid J. The internalization of professional nursing values in baccalaureate nursing students. Journal of Professional Nursing. 2018;34(1):25-30.

22. Karadag A, Hisar F, Baykara ZG, Caliskan N, Karabulut H, Ozturk D. A longitudinal study on the effect of tailored training and counseling on the professional attitude of nursing students. Journal of Professional Nursing. 2015;31(3):262270.

23. Koç Z, Bal C, Sağlam Z. Erkek öğrenci hemşirelerin hemşirelik mesleğini algılama durumlarının belirlenmesi. Maltepe Üniversitesi Hemşirelik Bilim ve Sanatı Dergisi, 2010; (Sempozyum Özel Sayıs1):318-323.

24. Dikmen YD, Yönder M, Yorgun S, Usta YY, Umur S, Aytekin, A. Hemşirelerin profesyonel tutumları ile bunu etkileyen faktörlerin incelenmesi. Anadolu Hemşirelik ve Sağlık Bilimleri Dergisi. 2014;17(3):158-164.

25. Pınar ŞE, Cesur B, Duran Ö, Güler E, Üstün Z, Abak G. Ebelik öğrencilerinin mesleki profesyonellikleri ve etkileyen etmenlerin incelenmesi. Fırat Sağlık Hizmetleri Dergisi 2013;8(23):1937.

26. Chiu CH, Yi Lu H, Arrigo LG, Wei CJ, Tsai D. Professionalism survey of medical students in Taiwan. J Exp Clin Med. 2010;2(1):35-42.

27. Lui MH, Lam L, Lee IF, Chien WT, Chau JP, Ip WY. Professional nursing values among baccalaureate nursing students in Hong Kong. Nurse Education Today. 2008;28(1):108-114. 
Tablo 1. Öğrencilerin tanıtıcı bilgilerinin dağılımı $(\mathrm{N}=180)$.

\begin{tabular}{|c|c|c|c|}
\hline & Değișkenler & $\mathbf{n}$ & $\%$ \\
\hline Cinsiyet & $\begin{array}{l}\text { Kiz } \\
\text { Erkek }\end{array}$ & $\begin{array}{l}129 \\
51\end{array}$ & $\begin{array}{l}71,7 \\
28,3\end{array}$ \\
\hline Yaş Ortalaması & & & \\
\hline Sinıf & $\begin{array}{l}\text { Üçüncü sınıf } \\
\text { Dördüncü sınıf }\end{array}$ & $\begin{array}{l}115 \\
65\end{array}$ & $\begin{array}{l}63,9 \\
36,1\end{array}$ \\
\hline Mezun Olunan Lise & $\begin{array}{l}\text { Düz lise } \\
\text { Sağlık Meslek Lisesi } \\
\text { Anadolu-Fen Lisesi } \\
\text { Diğer Meslek Liseleri }\end{array}$ & $\begin{array}{l}28 \\
35 \\
97 \\
20\end{array}$ & $\begin{array}{l}15,6 \\
19,4 \\
53,9 \\
11,1\end{array}$ \\
\hline $\begin{array}{l}\text { Hemşireliği İsteyerek Tercih Etme } \\
\text { Durumu }\end{array}$ & $\begin{array}{l}\text { Evet } \\
\text { Hayır }\end{array}$ & $\begin{array}{l}115 \\
65\end{array}$ & $\begin{array}{l}63,9 \\
36,1\end{array}$ \\
\hline Hemşireliği Sevme Durumu & $\begin{array}{l}\text { Evet } \\
\text { Hayır } \\
\text { Kararsızım }\end{array}$ & $\begin{array}{l}123 \\
29 \\
28\end{array}$ & $\begin{array}{l}68,3 \\
16,1 \\
15,6\end{array}$ \\
\hline $\begin{array}{l}\text { Alınan Mesleki Eğitimin Profesyonel } \\
\text { Davranışları Geliş̧irmede Etkisi }\end{array}$ & $\begin{array}{l}\text { Evet } \\
\text { Hayır } \\
\text { Kararsizım }\end{array}$ & $\begin{array}{l}106 \\
33 \\
41\end{array}$ & $\begin{array}{l}58,9 \\
18,3 \\
22,8\end{array}$ \\
\hline Mesleği Değiştirmeyi Düşünme Durumu & $\begin{array}{l}\text { Evet } \\
\text { Hayır } \\
\text { Kararsızım } \\
\end{array}$ & $\begin{array}{l}67 \\
84 \\
29 \\
\end{array}$ & $\begin{array}{l}37,2 \\
46,7 \\
16,1 \\
\end{array}$ \\
\hline
\end{tabular}


Tablo 2. Öğrencilerin HÖPTÖ ve alt boyutlarından aldıkları puan ortalamaları (N=180).

\begin{tabular}{|l|c|c|}
\hline HÖPTÖ ve Alt Boyutları & Ort. \pm SS & Minimum-Maximum Puan \\
\hline Sağlık Bakım Uygulamaları & $80,72 \pm 8,67$ & $37-90$ \\
\hline Aktivite Uygulamaları & $28,88 \pm 3,75$ & $15-35$ \\
\hline Raporlama & $8,34 \pm 1,77$ & $2-10$ \\
\hline Toplam HÖPTÖ & $\mathbf{1 1 7 , 9 5} \pm \mathbf{1 2 , 8 4}$ & $\mathbf{5 6 - 1 3 5}$ \\
\hline
\end{tabular}

HÖPTÖ:Hemşirelik Öğrencileri Profesyonel Davranış Ölçeği; Ort. $\pm S S:$ Ortalama \pm Standart sapma. 
Tablo 3. Öğrencilerin tanıtıcı özellikleri ile HÖPTÖ toplam puan ortalamalarının karşılaştırılması.

\begin{tabular}{|c|c|c|c|c|}
\hline & Değişkenler & $\begin{array}{c}\text { HÖPTÖ } \\
\text { Ort. } \pm \text { SS }\end{array}$ & İstatiksel test & $p$ \\
\hline Cinsiyet & $\begin{array}{l}\text { K1z } \\
\text { Erkek }\end{array}$ & $\begin{array}{c}120,72 \pm 9,86 \\
110,92 \pm 16,46\end{array}$ & $Z:-3,958$ & $\mathbf{0 , 0 0 0}$ \\
\hline Sinıf & $\begin{array}{l}\text { Üçüncü sınıf } \\
\text { Dördüncü sınıf }\end{array}$ & $\begin{array}{l}118,60 \pm 10,84 \\
116,78 \pm 15,79\end{array}$ & Z: $-0,001$ & 0,999 \\
\hline Mezun Olunan Lise & $\begin{array}{l}\text { Düz lise } \\
\text { Sağlık Meslek Lisesi } \\
\text { Anadolu-Fen Lisesi } \\
\text { Diğer Meslek Liseleri }\end{array}$ & $\begin{array}{c}121,32 \pm 10,42 \\
119,71 \pm 10,91 \\
115,56 \pm 14,43 \\
121,30 \pm 8,22\end{array}$ & K-W: 6,879 & 0,076 \\
\hline $\begin{array}{l}\text { Hemşireliği İsteyerek Tercih Etme } \\
\text { Durumu }\end{array}$ & $\begin{array}{l}\text { Evet } \\
\text { Hayır }\end{array}$ & $\begin{array}{l}119,61 \pm 11,57 \\
115,00 \pm 14,45\end{array}$ & $Z:-2,153$ & $\mathbf{0 , 0 3 1}$ \\
\hline Hemşireliği Sevme Durumu & $\begin{array}{l}\text { Evet } \\
\text { Hayır } \\
\text { Kararsızım } \\
\end{array}$ & $\begin{array}{l}120,48 \pm 11,02 \\
111,89 \pm 13,29 \\
113,07 \pm 16,35 \\
\end{array}$ & $\mathrm{~K}-\mathrm{W}: 14,897$ & 0,001 \\
\hline $\begin{array}{l}\text { Alınan Mesleki Eğitimin Profesyonel } \\
\text { Davranışları Geliştirmede Etkisi }\end{array}$ & $\begin{array}{l}\text { Evet } \\
\text { Hayır } \\
\text { Kararsızım }\end{array}$ & $\begin{array}{c}121,38 \pm 9,75 \\
112,84 \pm 17,65 \\
113,17 \pm 12,75\end{array}$ & $\mathrm{~K}-\mathrm{W}: 16,354$ & $\mathbf{0 , 0 0 0}$ \\
\hline $\begin{array}{l}\text { Mesleği Değiştirmeyi Düşünme Duru- } \\
\text { mu }\end{array}$ & $\begin{array}{l}\text { Evet } \\
\text { Hayır } \\
\text { Kararsızım }\end{array}$ & $\begin{array}{l}114,25 \pm 14,29 \\
121,26 \pm 11,02 \\
116,89 \pm 12,08 \\
\end{array}$ & $\mathrm{~K}-\mathrm{W}: 13,271$ & $\mathbf{0 , 0 0 1}$ \\
\hline
\end{tabular}

HÖPTÖ: Hemşirelik Öğrencileri Profesyonel Davranış Ölçeği; Ort. $\pm S S:$ Ortalama \pm Standart sapma;

Z: Mann-Whitney U testi; $K$-W: Kruskal-Wallis testi 